\title{
A Review of Muscle Tone Alteration on Post Stroke Patient
}

\author{
Gandu Eko Julianto Suyoso ${ }^{1, *}$, Veronika Vestine ${ }^{2}$, Angga Rahagiyanto ${ }^{3}$ \\ ${ }^{1,2,3}$ Health Information Management Study Program, Politeknik Negeri Jember, Indonesia \\ *Corresponding author. Email: gandu.eko.js@polije.ac.id
}

\begin{abstract}
Stroke is the second leading cause of death and the third disability in the world. Basic health research in Indonesia in the last 12 years shows that the prevalence of stroke is still high. A stroke occurs when a blood vessel in the brain is blocked or bursts, so that part of the brain does not get a blood supply and leads to cell death. A patient can avoid death but can still have the risk of experiencing a permanent or temporary disability that affects their productivity. One of the signs of disability in stroke patients is a change in muscle tone. The socioeconomic impact of stroke on a country is so enormous that it needs serious attention both in prevention and treatment. This review aimed to find out and review the development of research related to stroke, especially regarding risk factors, clinical manifestations, and muscle spasticity in post-stroke patients. Article writing was done by summarizing and analyzing the muscle tone of post-stroke patients. The sources of literature were from national and international journal providers by using the keywords "stroke risk factor, "stroke clinical feature", and "muscle tone related to post-stroke spasticity". This review concluded that there is an increase in muscle tone in post-stroke patients that causes muscle spasticity. This increased muscle tone can also be a sign of suboptimal therapy in stroke patients. It is hoped that there will be a wearable device developed to detect muscle tone that is concise and easy to use by the therapist or the patient's family.
\end{abstract}

Keywords: Muscle Tone, Post Stroke, Patient, Spasticity

\section{INTRODUCTION}

The first recorded use of "stroke", which was related to the Greek word "aplopexia", was in 1599 [1]. Stroke is characterized by a neurological disorder attributed to an acute injury of the central nervous system. "Stroke" is broadly used to include all the following conditions: CNS infarction, silent CNS infarction, intracerebral haemorrhage, silent cerebral haemorrhage, subarachnoid haemorrhage, cerebral venous thrombosis [2].

Stroke still becomes a health problem in both developed and developing countries [3]. There are currently more than 80 million people worldwide who have suffered a stroke, and there are more than 13.7 million new strokes each year [4,5]. Five and a half million people die from stroke each year, and each year more than 116 million years of healthy life are lost to deaths related to stroke and disability [4]. Basic health research in Indonesia in the last 12 years shows that the prevalence of stroke is still high [3].

The impact of stroke is extraordinary for the country. Stroke is the third leading cause of death in Indonesia, followed by diabetes mellitus and hypertension, with a mortality rate of 138,268 people or $9.7 \%$ of the total deaths. A patient can avoid death by stroke, but they still have the risk of experiencing a permanent or temporary disability that affects their productivity. Aside from mortality, stroke disability represents an economic burden on families and weighs on emotional and mental burdens that hinder the productivity of other family members. This creates a double burden in overcoming health problems in Indonesia. This is also related to the slow decline in the incidence of communicable diseases and tends to persist and the incidence of non-communicable diseases that progress quite rapidly $[3,6]$. The socioeconomic 
impact of stroke on a country is so enormous that it needs serious attention both in prevention and treatment.

The risk factors of stroke are so many, as well as the mortality and disability caused by stroke. The duration, cost, and quality of treatment are considered to be the main contributing factors to the high mortality and disability caused by stroke. With higher stroke treatment costs than Malaysia, Indonesia can only reduce the mortality prevalence ratio to 0.16 and the stroke prevalence ratio to 2.80 . This shows the need to improve the stroke management system in Indonesia [7]. One method to improve the treatment quality for spasticity is by measuring the muscle tone of post-stroke patients. But before we develop the tool, we need to dig into the stroke risk factor, stroke clinical feature, and especially muscle tone related to post-stroke spasticity.

\section{METHOD}

The purpose of this article is to find out and review the development of research related to stroke, especially regarding risk factors, clinical manifestations, and muscle spasticity in post-stroke patients. This paper also laid the groundwork for further research by the author, creating wearable technology for detecting muscle tone that is both concise and simple for the therapist and the patient's family to use. Article writing was done by summarizing and analyzing the articles that were related to stroke. The sources of literature were from national and international journal providers at Thieme, ScienceDirect, Pubmed, etc., by using the keywords "stroke risk factor," "stroke clinical feature," and " muscle tone related to post-stroke spasticity". The articles that fit the subject of the review were then reviewed by paraphrasing the core and common thread of the research. The details of the articles that have been revised and paraphrased were described in Table 1.

Table 1. Details of the search method results for articles with specific keywords

\begin{tabular}{clcc}
\hline No. & \multicolumn{1}{c}{ Keyword } & Total & Reference \\
\hline 1 & Stroke risk factor & 8 & {$[5],[8],[9],[10],[11],[12],[13],[14]$} \\
\hline 2 & Stroke clinical feature & 2 & {$[15],[16]$} \\
\hline 3 & $\begin{array}{l}\text { Muscle tone related to post-stroke } \\
\text { spasticity }\end{array}$ & 5 & {$[17],[18],[19],[20],[21],[22]$} \\
\hline
\end{tabular}

\section{RESULTS AND DISCUSSION}

\subsection{Stroke Risk Factor}

Identifying risk factors for stroke is made difficult by the fact that stroke comes in many varieties. A stroke occurs when a blood vessel in the brain is blocked (ischemic) or bursts (hemorrhagic). The majority of strokes are ischemic, although the relative burden of hemorrhagic versus ischemic stroke varies between different population groups. Although there are some similarities in the risk factors for hemorrhagic and ischemic strokes, there are some significant differences. In general, stroke risk factors are divided into two groups, namely modifiable factors, genetic factors, and nonmodifiable factors. Genetic risk factors are increasingly recognized as potentially changeable, either directly or through alteration of gene-environment interactions. Therefore, genetics is put in an overlapping area between modifiable and nonmodifiable to highlight this reality [8].

Age, sex, and race-ethnicity are nonmodifiable risk variables (also known as risk indicators) for stroke. Stroke is, in general, an aging illness. The risk of stroke rises with age, with the risk doubling every decade beyond 55, but new data shows that the risk of ischemic stroke is growing in the 20 to 54-year-old age range. Women have the same or higher risk of stroke as men at early ages; however, the proportional risk is somewhat higher for males as they get older. The increased risk of stroke in younger women is most likely due to hazards associated with pregnancy and the postpartum period and other hormonal variables such as the use of hormonal contraceptives. Race, compared to their white counterparts, blacks have double the risk of incident stroke and have a greater death rate associated with stroke. In some cohorts, Hispanic/Latino Americans have an elevated risk of stroke [8].

Modifiable risk factors of stroke consist of several clusters. Physiological risk factors include hypertension, obesity, diabetes mellitus, dyslipidemia, and kidneys disfunction. The most important risk of the physiological factor for all stroke subtypes was hypertension, which was a more potent risk factor for intracerebral haemorrhagic stroke than ischemic stroke and was 
more critical in those aged 45 and younger. Behaviour risk factors, including a diet high in sodium and red meat, a diet low in fruit and vegetable, alcohol consumption, tobacco smoking, and low physical activity. Environmental risk factors, including air pollutants $\left(\mathrm{PM}_{2,5}, \mathrm{PM}_{10}, \mathrm{O}_{3}\right.$, $\mathrm{NO}_{2}, \mathrm{CO}$, and $\mathrm{SO}_{2}$ ), metal pollutants (lead, cadmium, mercury), and second-hand smoke. The last one is psychosocial risk factors; however, the magnitude of the effect and whether it would be deemed a clinically meaningful impact remain unknown [5,8-14].

Table 2. Stroke clinical feature on each localization

\subsection{Stroke Clinical Feature}

The neurological effects of a stroke vary depending on which part of the brain is damaged. Therefore, knowledge of cerebral vascular anatomy and the locations of different functions inside the brain are required for localization. The localization is divided into four clusters: anterior cerebral artery, middle cerebral artery, vertebrobasilar, and small-vessel occlusion $[15,16]$. The stroke clinical feature of each localization is described in Table 2.

\begin{tabular}{ll}
\hline Localization & Clinical Feature \\
\hline Anterior cerebral artery & Leg more than arm involvement with hand \\
sparing & Urinary incontinence \\
& Gait apraxia \\
& Akinetic mutism \\
\hline Middle cerebral artery & Homonymous hemianopia/quadrantanopia \\
& (involvement of inferior division) \\
& Face-arm- leg involvement \\
& Aphasia (Broca's = superior division; Wernicke's \\
& $=$ inferior division) \\
& Inattention \\
& Gaze paralysis (usually indicates a large area of \\
& frontal damage) \\
Occipital lobe - homonymous hemianopia, \\
cortical blindness, other cortical visual deficits \\
Cerebellum - ataxia, nystagmus \\
Brainstem cranial nerve palsies - diplopia, facial \\
numbness/ weakness, vertigo, dysphagia, \\
dysphonia \\
Spinal tracts - hemiparesis and hemisensory loss \\
Pure motor hemiparesis \\
Pure sensory stroke \\
Sensorimotor stroke \\
Ataxic hemiparesis \\
\end{tabular}

\subsection{Post-Stroke Spasticity}

Stroke has many complications, including musculoskeletal, neurological, psychological, skin, etc. Spasticity is one of many neurological complications after stroke [17]. It is defined by a velocity-dependent increase in resistance during passive stretch as a result of the stretch reflex's hyperexcitability. Spasticity frequently causes immobility of a joint due to decreased muscle length, resulting in contracture [18].

Spasticity is common after stroke. The researcher estimates post-stroke spasticity prevalence was highly variable, ranging from $4 \%$ to $42.6 \%$, with the prevalence of disabling spasticity ranging from $2 \%$ to $13 \%$ [19]. The onset of spasticity in the post-stroke era is very varied, with studies showing that spasticity develops and peaks at 1-3 months following a stroke. Although the neural components of spasticity peak three months after a stroke, the muscular components of spasticity may grow over time, leading to an increase in spasticity at six months post-stroke [20].

One of the upper motor neuron disorders that cause hypertonia is spasticity. Muscle tone abnormalities can be caused by any lesion or injury along the pyramidal tract or extrapyramidal fibers. The local activation of muscle spindles causes spasticity, but it requires the participation of the central nervous system to propagate and manifest. Damage to the upper motor neurons causes a breakdown in communication between the brain 
and the spinal cord, resulting in net disinhibition of the spinal reflexes. When a patient's muscles are stretched passively, sensory input from muscle spindles is sent to the spinal cord via primary group Ia afferent fibers, and alpha-motoneurons are activated, resulting in a loss of supra-spinal inhibitory control and excessive muscular activation [20].

At a seven-year follow-up, one-third of ischemic stroke patients under 70 had increased muscular tone. Classic spasticity was also present in half of them. Increased muscle tone post-stroke was predicted by age, arm paresis, aphasia, and facial palsy at the time of the index stroke. This may indicate sub-optimal treatment, related to use, but also to intensity, duration, and frequency, of interventions such as physiotherapy, surgery, and pharmacological treatments [21].

Spasticity places a significant strain on patients and caregivers [22]. In addition, spasticity has a big impact on the patient's activities of daily living and health-related quality of life [23]. The good news is that spasticity can be measured in clinical and quantitative evaluation methods [24]. This assessment can be beneficial in monitoring poststroke patients' muscle tone to avoid stiffness and assessing therapy efficacy.

\section{CONCLUSION}

Stroke is a neurological illness caused by central nervous system damage that occurs suddenly. There are both controllable and nonmodifiable risk factors for stroke. The clinical signs of a stroke are determined by where the central nervous system lesion occurs. Muscular spasticity, characterized by an increase in muscle tone, is one of the clinical signs that might develop. This rise in tone might potentially suggest that your treatment is not working. Based on the unpredictability of muscle spasticity's development and the potential of life-threatening, debilitating, and costly repercussions for patients and their families, it's critical to prevent and treat muscle spasticity as soon as feasible. Measuring the muscular tone of the stroke patient by the family or therapist is one approach to detecting spasticity. This article is expected to be the basis for developing a wearable tool to measure the patient's muscle tone.

\section{ACKNOWLEDGMENT}

The author would like to thank the Department of Health, Politeknik Negeri Jember so that this review of article can be realized and beneficial for the development of science.

\section{REFERENCES}

[1] Coupland AP, Thapar A, Qureshi MI, Jenkins $\mathrm{H}$, Davies AH. The definition of stroke. J R Soc Med. 2017;110(1):9-12.

[2] Sacco RL, Kasner SE, Broderick JP, Caplan LR, Connors JJ, Culebras A, et al. An updated definition of stroke for the 21st century: A statement for healthcare professionals from the American heart association/American stroke association. Stroke. 2013;44(7):206489.

[3] Dian Saraswati R, Khariri. Transisi Epidemiologi Stroke sebagai Penyebab Kematian pada Semua Kelompok Usia di Indonesia. Semin Nas Ris Kedokt (SENSORIK II [Internet]. 2021;2(1):2021. Available from: https://conference.upnvj.ac.id/index.php/senso rik/article/view/1001

[4] Lindsay MP, Norrving B, Sacco RL, Brainin M, Hacke W, Martins S, et al. World Stroke Organization (WSO): Global Stroke Fact Sheet 2019. Int J Stroke. 2019;14(8):806-17.

[5] Feigin VL, Nichols E, Alam T, Bannick MS, Beghi E, Blake N, et al. Global, regional, and national burden of neurological disorders, 1990-2016: a systematic analysis for the Global Burden of Disease Study 2016. Lancet Neurol. 2019;18(5):459-80.

[6] Riyadina W, Pradono J, Kristanti D, Turana Y. Stroke in Indonesia: Risk factors and predispositions in young adults. J Cardiovasc Dis Res. 2020;11(2):178-83.

[7] Wijaya HR, Supriyanto E, Salim MIM, Siregar KN, Eryando T. Stroke management cost: Review in Indonesia, Malaysia and Singapore. AIP Conf Proc. 2019;2092(April):1-8.

[8] Boehme AK, Esenwa C, Elkind MSV. Stroke Risk Factors, Genetics, and Prevention. Circ Res. 2017;120(3):472-95.

[9] Hill VA, Towfighi A. Modifiable Risk Factors for Stroke and Strategies for Stroke Prevention. Semin Neurol. 2017;37(3):23758.

[10] O'Donnell MJ, Denis X, Liu L, Zhang H, Chin SL, Rao-Melacini P, et al. Risk factors for ischaemic and intracerebral haemorrhagic stroke in 22 countries (the INTERSTROKE study): A case-control study. Lancet. 2010;376(9735):112-23.

[11] Hasnah F, Lestari Y, Abdiana A. The risk of 
smoking with stroke in Asia : meta-analysis. J Profesi Med J Kedokt dan Kesehat. 2020;14(1):111-7.

[12] Aigner A, Grittner U, Rolfs A, Norrving B, Siegerink B, Busch MA. Contribution of Established Stroke Risk Factors to the Burden of Stroke in Young Adults. Stroke. 2017;48(7):1744-51.

[13] Lightbody CE, Clegg A, Patel K, Lucas JC, Storey H, Hackett ML, et al. Systematic Review and Meta-Analysis of Psychosocial Risk Factors for Stroke. Semin Neurol. 2017;37(3):294-306.

[14] Graber M, Mohr S, Baptiste L, Duloquin G, Blanc-Labarre C, Mariet AS, et al. Air pollution and stroke. A new modifiable risk factor is in the air. Rev Neurol (Paris). 2019;175(10):619-24.

[15] Murphy SJ, Werring DJ. Stroke: causes and clinical features. Med (United Kingdom) [Internet]. 2020;48(9):561-6. Available from: https://doi.org/10.1016/j.mpmed.2020.06.002

[16] Markus H. Stroke: causes and clinical features. Medicine (Baltimore) [Internet]. 2008;36(11):586-91. Available from: http://dx.doi.org/10.1016/j.mpmed.2008.08.00 9

[17] Bartels MN, Duffy CA, Beland HE. Pathophysiology, medical management, and acute rehabilitation of stroke survivors [Internet]. Fourth Edi. Stroke Rehabilitation. Elsevier Ltd; 2015. 2-45 p. Available from: http://dx.doi.org/10.1016/B978-0-323-172813.00001-0

[18] Li S, Francisco GE. New insights into the pathophysiology of post-stroke spasticity. Front Hum Neurosci. 2015;9(APRIL):1-9.

[19] Wissel J, Manack A, Brainin M. Toward an epidemiology of poststroke spasticity. Neurology. 2013;80(3 SUPPL.2):13-20.

[20] Kuo CL, Hu GC. Post-stroke Spasticity: A Review of Epidemiology, Pathophysiology, and Treatments. Int $\mathrm{J}$ Gerontol [Internet]. 2018;12(4):280-4. Available from: https://doi.org/10.1016/j.ijge.2018.05.005

[21] Persson CU, Holmegaard L, Redfors P, Jern $\mathrm{C}$, Blomstrand C, Jood K. Increased muscle tone and contracture late after ischemic stroke. Brain Behav. 2020 Feb 1;10(2).

[22] Ward AB. A literature review of the pathophysiology and onset of post-stroke spasticity. Eur J Neurol. 2012;19(1):21-7.
[23] Schinwelski MJ, Sitek EJ, Wąż P, Sławek JW. Prevalence and predictors of post-stroke spasticity and its impact on daily living and quality of life. Neurol Neurochir Pol. 2019;53(6):449-57.

[24] Petek Balci B. Spasticity measurement. Arch Neuropsychiatry. 2018;(Supplement 1):49-53. 